\title{
Conception of family and friends on euthanasia in intensive care unit in Greece
}

\author{
Tania Triantafyllou ${ }^{1 *}$, Nikolaos Giakis ${ }^{2}$, Elisavet Polychronopoulou ${ }^{3}$, Michael Demosthenous ${ }^{4}, S_{\text {Stylianos Karatzas }}^{5}$, \\ Spyridon Stergiopoulos ${ }^{1}$, Georgios Zografos ${ }^{1}$ and Dimitrios Theodorou ${ }^{1}$
}

\begin{abstract}
Background: Euthanasia poses a hot topic of argument in all modern societies. While in several countries the law allows euthanasia under certain conditions, in others, such as Greece, there is no established legal background. This is essentially derived from the conflict on the right to life, which is constitutionally guaranteed. The purpose of this study was to investigate the attitude of relatives or friends of critically ill patients hospitalized in the Intensive Care Unit (ICU) towards euthanasia in a Greek hospital.
\end{abstract}

Methods: This is a prospective study based on questionnaires completed by relatives and friends of patients hospitalized in the ICU. Relatives/friends of critically ill patients hospitalized in the ICU with APACHE Score $\geq 20$ completed a questionnaire consisting of information about their relationship to the patient and another part with psychometric questions on euthanasia. SPSS 19.0 was used for analysis of the data.

Results: One hundred forty-three questionnaires were collected (50.7\% female, 33.6\% patients' parents). 62.9\% of responders considered the quality of life (QOL) of the patient more important compared to the value of life. $48.3 \%$ were in favor of euthanasia and $66.4 \%$ knew little about euthanasia. $48.3 \%$ agreed in institutionalizing euthanasia under certain circumstances. Consensus to discontinue the therapeutic interventions significantly correlated to patient's age and severity of the disease.

Conclusions: In the present study we found that the more the APACHE II score increased the more positive were the participants when asked to give consent or decide to accelerate the end of life of the patient. Overall, the level of knowledge of the relatives of critically ill patients on euthanasia and the currently used law in Greece on euthanasia is poor.

Keywords: Euthanasia, Critically ill patient, Intensive care unit

\section{Background}

The problem of euthanasia has been a matter of concern for humanity since antiquity. The importance of the end of life was firstly introduced by Hippocrates, who added "moral practice" of medicine in the oath, condemning the administration of a lethal drug from the physician to his patient, either in order to put an end to his life or to the life of any unborn fetus.

Development of medical science, rapid evolution of medical technology and progress in Intensive Care Unit (ICU) medicine offered the potential to effectively treat

\footnotetext{
* Correspondence: t_triantafilou@yahoo.com

${ }^{1} 1$ st Department of Surgery, University of Athens, Hippocration General Hospital of Athens, 11527 Athens, Greece

Full list of author information is available at the end of the article
}

diseases, further expand life expectancy, and reduce transmitted diseases. Under these conditions, significant ethical and legal problems have emerged, both in the treatment of many diseases and the dilemma of continuation or withdrawal of treatment intervention.

Euthanasia is defined as "end to life out of mercy", in end-stage disease, or situations due to which life becomes particularly unpleasant or unbearable. The term "euthanasia" comes from ancient Greece when a different meaning was initially proposed. In ancient times, what intrigued the Greeks the most was great and glorious death in order to give to the diseased immortality and fame after death. In the original concept of euthanasia, the word "eu" means good, beautiful, brave, noble, while the second part of the word expresses the natural 
"death". Euthanasia sets an end to life on request and is defined as the process where a doctor intentionally gives an end to the life of a person by the administration of drugs, under the voluntary and competent request of that person, who lacks intent to cure.

Francis Bacon (1561-1626) translated the Greek word euthanasia in English clarifying the meaning as "enhancing death, to put an end to a life full of pain and intolerance." Euthanasia is defined as "the deliberate killing incurable, with his consent or without it, in relief or redemption of the painful agony of unbearable pain existing therapies fail to soothe". In other words, this "death inducing method is done for specific reasons".

Depending on how euthanasia is performed, the term can be further classified based on the subject who takes initiative and the way euthanasia is executed.

Euthanasia has been further investigated in several forms and has been divided according to social issues and values, due to scientific progress or the complexity of the methods used to overcome the legal and ethical responsibilities.

Recently, "early euthanasia of defective neonates", like infants who develop serious health problems, has been widely discussed via highlighting the growing interest of legal science and public opinion. This action is not a form of euthanasia. In fact, proponents of this practice argue that this kind of euthanasia belongs to the concept of abortion, but does not lose the independent character as a form of euthanasia.

A separate type of euthanasia is the field of disconnection of patient from artificial life-sustaining machines. This action is often characterized as a form of passive euthanasia, which is not accurate, as the disconnection of the patient reflects an action. In fact, this form is similar to active euthanasia which is a possibly unfair human action. In order to be accepted as a type of euthanasia, disruption of technical means of life support must fulfill two conditions, pre-existing patient declaration of his/her intent and the progressive aggravation of patient's condition with likely fatal consequences in contrast to previous permanent and steady state.

"Assisted suicide" is considered as another aspect of euthanasia and is actually defined as the action of providing a form of medication with toxic effect on human body aiming to terminate life in its critical end-stage condition. Moreover, the respect to the right in autonomy and self-determination has been a field of controversy. In the literature it has been referred as "Wills Euthanasia", "Living Will", "Advance directives for end of life" and "Biological Wills". Their content is medical advice based on which the patient refuses or accepts in advance specific treatments that will be proposed in the future by the physician. This advice contains further information on the expected course of the disease and gives the potential of selection of a specific person as a representative of the patient in his/her personal health matters in the case patient's ability to judge and take decisions for his/her life becomes impossible in the future.

Conflict on euthanasia definition and aspects is initially derived from the arguments on the right to life, which is internationally protected and widely guaranteed constitutionally. Interestingly, relevant provisions such as the European Convention for the Protection of Human Rights, the European Court of Human Rights and the European Oviedo Convention (1997) on Human Rights and Biomedicine have been extensively occupied with the issues aforementioned.

Dilemmas on euthanasia have gained medical, legal, political, social and economical aspects. In the Netherlands, regulation of euthanasia has been officially established, while in Luxembourg euthanasia was legalized by the parliament in 2008 and the official adoption was announced in 2009 [1]. Australia enacted the "Act on patient rights in the last stage," or more simply the legitimacy of "active, voluntary euthanasia" [2, 3]. The first US state allowing medically assisted suicide, was Oregon by adopting the Law "death with dignity" (Death with Dignity, Act of 1994) but under strict conditions [4]. In 2008, Washington State allowed in similar conditions to those of Oregon, euthanasia. In addition, the state of Montana, allowed euthanasia, after a court decision in December 2008 [5].

Controversial opinion on the establishment of the right to euthanasia in Greece is of particular interest since there is no relevant legislation. The Greek legislation does not contain the term "euthanasia" beyond the term "homicide in consent" which consists of an offense of Criminal Law. Greece has signed the Treaty on Human Rights and Biomedicine in Oviedo, Spain.

The Greek Orthodox Church has a precise position against all forms of euthanasia, claiming the protection of life to the fullest and considering life as a sacred gift from God.

The purpose of this study is to investigate the attitude and adequacy of knowledge of relatives or friends of patients hospitalized in an ICU towards euthanasia and to identify and evaluate possible factors affecting their decisions about possible euthanasia.

\section{Methods}

The study was conducted in a tertiary Greek hospital from 01.03.2012 until 28.02.2015. For the present study, we used the definition of passive euthanasia. The individuals included in the study were relatives or friends of patients (aged between 18 and 80 years old) hospitalized in the ICU on mechanical ventilation, for at least ten days without intension for weaning from the ventilator. The severity of patients' condition was estimated using 
the APACHE II score and there were only included patients with APACHE II score $>20$. In fact, this score is widely used as a scoring system of the severity of the disease specifically among ICU patients. It takes under consideration the age of the patient, the neurological assessment based on the Glasgow Coma Scale and several physiological measurements like vital signs (temperature, mean arterial pressure, heart rate, respiratory rate), blood tests (creatinine, hematocrit, white blood cell count, serum sodium and potassium) and $\mathrm{pH}$ of the arterial blood.

All participants were given a questionnaire after being informed about the purpose of the study and that their participation would be voluntary and anonymous. They returned the questionnaire inside a sealed envelope.

The questionnaire consisted of two parts. The first part clarified the demographics of relatives/friends as well as their relationship with the patient. The second part consisted of three psychometric questions that assessed their knowledge on euthanasia and scored a five- point Likert scale from "very few $=1$ to very much $=5$ ". There were seven questions on their attitude towards the possibility of euthanasia of the patient which was scored on a five- point Likert scale characterized as "strongly disagree $=1$ to strongly agree $=5 "$, a question that evaluated their current attitude towards the past (YES-NO) and one question with eleven sub-questions that evaluated the factors that would affect their assumingly positive decision in the Likert scale (not at all important $=1$ to very important $=5$ ).

The study was independently reviewed and approved by the Ethical Committee of our hospital and it conforms to the provisions of the Declaration of Helsinki in 1995 (as revised in 2002). All participants signed an informed consent in order to be included in the study. Patient anonymity was preserved.

\section{Statistical analysis}

The mean values and standard deviations (SD) were used to describe quantitative variables. Absolute $(\mathrm{N})$ and the relative (\%) frequencies were used for the description of qualitative variables. For comparison of the ratios we used Pearson's $x^{2}$ test or Fisher's exact test where appropriate. To control the type I error due to multiple comparisons, the Bonferroni correction was used where the level of significance was set as $0.05 / \mathrm{n}(\mathrm{n}=$ number of comparisons). To compare quantitative variables between two groups we used the Student's t-test. For the control of the relationship between two quantitative variables we used the Spearman ( $r$ ) correlation. The correlation is considered as low when ranges between 0.1 and 0.3 , moderate between 0.31 and 0.5 and high when above 0.5 . In order to find independent factors associated with the views of participants on euthanasia, logistic regression analysis was used with successive stepwise odds ratio with $95 \%$ confidence intervals $(95 \% \mathrm{CI})$. The interval reliability of the questionnaires was tested using the Cronbach's- $\alpha$ factor. Evaluation of answers to the questionnaire provided required Cronbach's alpha test. The level of significance was set at 0.05. SPSS 19.0 was used for analysis.

\section{Results}

The population studied consisted of 143 subjects (50.7\% females) with a mean age of 43.1 years $( \pm 13.8)$. Data collection lasted for three years, from 01.03.2012 until 28.02.2015. A total of 579 questionnaires was collected, 143 of which were adequately completed. Therefore, response rate was $24.70 \%$.

In regards of responders' characteristics and their relationship to patients in the ICU, $33.6 \%(n=48)$ of the sample consisted of the parents of the patient hospitalized in the ICU, $18.9 \%(n=27)$ were patient's partner, $18.9 \%(n=27)$ were friends, $16.8(n=24)$ were relatives, $10.5 \%(n=15)$ were colleagues and $1.4 \%(n=2)$ were in another relationship with the patient. The majority of participants (66.4\%) lived in a different house from the patient, while among the rest, $77.3 \%$ lived in the same village/town. Additionally, $47.6 \%(n=68)$ of participants were married, $30.8 \%(n=44)$ were single and the rest were divorced, widowers or roommates, while $59.9 \%$ $(n=85)$ had children.

The mean APACHE II score of the patients hospitalized in the ICU was 24.9 points $(\mathrm{SD}=2.2)$. When associated to the intention of relatives or friends to decide on the possible end of life of the ICU patient, we found that high APACHE score of the patient increased the supportive to euthanasia opinion of the participants. In fact, for patients with APACHE score above 25, participants were positively inclined in regards of euthanasia.

Results of the study revealed that the level of knowledge on euthanasia of relatives/friends is low $(66.5 \%$ knew a few/very few) and only $11.2 \%$ knew much/very much. The main source was the media and press (78.9\%). Even more, $46.2 \%$ was not informed about the progress of legislation of euthanasia in Greece. More than half of the participants (48.3\%) would agree under certain conditions to legalize euthanasia in Greece, while $23.1 \%$ of the answers were inconclusive. Furthermore, nearly one in three participants (33.8\%) has changed his/her point of view on euthanasia compared to the initial position. In fact, $47.6 \%$ of participants would consent or take a decision to accelerate the end of life of the patient under certain conditions.

Table 1 shows the results of the 12-item questionnaire that was given to participants and Table 2 reflects the relationship between the responders' background on euthanasia and their attitude towards euthanasia. Interestingly, a significantly positive correlation between Q1 and Q3 questions was found ( $p<0,001, r=0.36)$. Herein, the 
Table 1 Knowledge and attitude of relatives/friends of patients to euthanasia

\begin{tabular}{|c|c|c|c|}
\hline & & Number & Percent \\
\hline \multirow[t]{5}{*}{ What do I know about Euthanasia? (Q1) } & Very few & 34 & 23,8 \\
\hline & A few & 61 & 42,7 \\
\hline & Some & 32 & 22,4 \\
\hline & Much & 14 & 9,8 \\
\hline & Very Much & 2 & 1,4 \\
\hline \multirow[t]{4}{*}{ Source of knowledge (Q2) } & Primary Studies & 21 & 14,8 \\
\hline & Post-graduate studies & 4 & 2,8 \\
\hline & Continous education & 5 & 3,5 \\
\hline & Media & 112 & 78,9 \\
\hline \multirow{5}{*}{$\begin{array}{l}\text { How informed are you about the law regarding } \\
\text { euthanasia in Greece? (Q3) }\end{array}$} & I am not informed & 66 & 46,2 \\
\hline & A Little & 53 & 37,1 \\
\hline & Average knoeledge & 20 & 14,0 \\
\hline & Well informed & 3 & 2,1 \\
\hline & Very informed & 1 & 0,7 \\
\hline \multirow{5}{*}{$\begin{array}{l}\text { Would you agree to stop a treatment applied to } \\
\text { your relative/friend, apart from the possibility that } \\
\text { this would briefly prolong his/her life, upon his/her } \\
\text { request and if this was permitted by law? (Q4) }\end{array}$} & Totally disagree & 30 & 21,0 \\
\hline & Disagree & 39 & 27,3 \\
\hline & Do not know & 36 & 25,2 \\
\hline & I agree & 32 & 22,4 \\
\hline & Totally agree & 6 & 4,2 \\
\hline \multirow{5}{*}{$\begin{array}{l}\text { Would you agree not to initiate a treatment, although } \\
\text { this could briefly prolong his/her life, upon his/her } \\
\text { request and if this was permitted by law? (Q5) }\end{array}$} & Totally disagree & 32 & 22,4 \\
\hline & Disagree & 48 & 33,6 \\
\hline & Do not know & 32 & 22,4 \\
\hline & I agree & 25 & 17,5 \\
\hline & Totally agree & 6 & 4,2 \\
\hline \multirow{5}{*}{$\begin{array}{l}\text { Would you agree in legislation of euthanasia in } \\
\text { Greece under certain conditions? (Q6) }\end{array}$} & Totally disagree & 19 & 13,3 \\
\hline & Disagree & 22 & 15,4 \\
\hline & Do not know & 33 & 23,1 \\
\hline & I agree & 59 & 41,3 \\
\hline & Totally agree & 10 & 7,0 \\
\hline \multirow{5}{*}{$\begin{array}{l}\text { Would you agree to stop a treatment applied to } \\
\text { your relative/friend, even if this would briefly prolong } \\
\text { his/her life, upon physicians' recommendation and } \\
\text { if this was permitted by law? (Q7) }\end{array}$} & Totally disagree & 25 & 17,5 \\
\hline & Disagree & 43 & 30,1 \\
\hline & Do not know & 39 & 27,3 \\
\hline & I agree & 31 & 21,7 \\
\hline & Totally agree & 5 & 3,5 \\
\hline \multirow{5}{*}{$\begin{array}{l}\text { Would you agree not to start a treatment to your } \\
\text { relative/friend, even if this would briefly prolong } \\
\text { his/her life, upon physicians' recommendation and } \\
\text { if this was permitted by law? (Q8) }\end{array}$} & Totally disagree & 26 & 18,2 \\
\hline & Disagree & 43 & 30,1 \\
\hline & Do not know & 36 & 25,2 \\
\hline & I agree & 34 & 23,8 \\
\hline & Totally agree & 4 & 2,8 \\
\hline \multirow{5}{*}{$\begin{array}{l}\text { Would you ask the physician to stop a treatment } \\
\text { applied to your relative/friend, even if this would } \\
\text { briefly prolong his life under certain circumstances? (Q9) }\end{array}$} & Totally disagree & 40 & 28,0 \\
\hline & Disagree & 65 & 45,5 \\
\hline & Do not know & 21 & 14,7 \\
\hline & I agree & 15 & 10,5 \\
\hline & Totally agree & 2 & 1,4 \\
\hline
\end{tabular}


Table 1 Knowledge and attitude of relatives/friends of patients to euthanasia (Continued)

\begin{tabular}{|c|c|c|c|}
\hline & & Number & Percent \\
\hline \multirow{5}{*}{$\begin{array}{l}\text { Would you ask the physician not to start a treatment } \\
\text { to your relative/friend, even if this would briefly prolong } \\
\text { his life under certain circumstances? (Q9) (Q10) }\end{array}$} & Totally disagree & 38 & 26,6 \\
\hline & Disagree & 66 & 46,2 \\
\hline & Do not know & 25 & 17,5 \\
\hline & I agree & 12 & 8,4 \\
\hline & Totally agree & 2 & 1,4 \\
\hline \multirow{2}{*}{$\begin{array}{l}\text { Has your current attitude towards euthanasia } \\
\text { changed compared to the initial opinion? (Q11) }\end{array}$} & Yes & 48 & 33,8 \\
\hline & No & 94 & 66,2 \\
\hline \multirow{2}{*}{$\begin{array}{l}\text { Would you ever agree or would you take a decision to } \\
\text { accelerate the end of the life of your relative/friend } \\
\text { under certain conditions? (Q12) }\end{array}$} & Yes & 68 & 47,6 \\
\hline & No & 75 & 52,4 \\
\hline
\end{tabular}

more the relatives/friends were aware about euthanasia in general, the better they knew about legislation in Greece. Even more, there seemed to be a significantly positive correlation between the range of information on the aforementioned law in Greece (Q3) and their supportive opinion in regards of patient's and/or physician's preference on treatment options and decisions, as expressed by questions Q7 $(p=0,016, \mathrm{r}=0,20)$ and Q8 $(p=0,020$, $r=0,19)$. In addition, awareness of relatives/friends of patients on currently established legislation in Greece was positively associated with their request to the therapeutic team either to discontinue $(p=0.025, r=0.19)$ or to even initially disincline any medical intervention $(p=0,038$, $r=0.17)$. Therefore, the more informed they were, the more acquiescent they presented with the idea of euthanasia. Finally there are significant positive correlations between all variables of the questionnaire and the attitude of relatives/friends towards euthanasia $(p<0,001)$ (Tables 1 and 2).

Furthermore, we investigated the conditions under which participants would consent to a decision to the end of life of their severely ill patient in descending order of importance. The three most important conditions in order to consent or to make such a decision was the confirmation of patient's irreversibly severe status, $(\mathrm{MT}=4.6 \mathrm{SD}=0,9)$, his/her intolerable pain $(\mathrm{MT}=4.6$, $\mathrm{SD}=0.7)$ and brain death $(\mathrm{MT}=4.5, \mathrm{SD}=1)$. The less important conditions were the active participation of the staff (MT $=3.3, \mathrm{SD}=1.5)$ and the persistence of family members $(\mathrm{MT}=2.6, \mathrm{SD}=1.3)$.

\section{Discussion}

Technological advances in the field of medicine and demographic changes have led to a more complicated

Table 2 Correlation of knowledge and attitude of relatives/friends to euthanasia

\begin{tabular}{|c|c|c|c|c|c|c|c|c|c|}
\hline & & Q3 & Q4 & Q5 & Q6 & Q7 & Q8 & Q9 & Q10 \\
\hline \multirow[t]{2}{*}{ Q1. } & $r$ & 0,36 & $-0,02$ & $-0,09$ & 0,07 & 0,03 & 0,08 & $-0,05$ & $-0,08$ \\
\hline & P & $<0,001$ & 0,782 & 0,290 & 0,407 & 0,744 & 0,323 & 0,533 & 0,316 \\
\hline \multirow[t]{2}{*}{ Q3. } & $r$ & 1,00 & 0,16 & 0,10 & 0,15 & 0,20 & 0,19 & 0,19 & 0,17 \\
\hline & P & . & 0,053 & 0,245 & 0,083 & 0,016 & 0,020 & 0,025 & 0,038 \\
\hline \multirow[t]{2}{*}{ Q4. } & $r$ & & 1,00 & 0,90 & 0,63 & 0,61 & 0,54 & 0,66 & 0,66 \\
\hline & P & & . & $<0,001$ & $<0,001$ & $<0,001$ & $<0,001$ & $<0,001$ & $<0,001$ \\
\hline \multirow[t]{2}{*}{ Q5. } & $r$ & & & 1,00 & 0,57 & 0,67 & 0,58 & 0,67 & 0,64 \\
\hline & P & & & & $<0,001$ & $<0,001$ & $<0,001$ & $<0,001$ & $<0,001$ \\
\hline \multirow[t]{2}{*}{ Q6. } & $r$ & & & & 1,00 & 0,49 & 0,47 & 0,49 & 0,51 \\
\hline & $P$ & & & & & $<0,001$ & $<0,001$ & $<0,001$ & $<0,001$ \\
\hline \multirow[t]{2}{*}{ Q7. } & $r$ & & & & & 1,00 & 0,87 & 0,60 & 0,58 \\
\hline & $P$ & & & & & & $<0,001$ & $<0,001$ & $<0,001$ \\
\hline \multirow[t]{2}{*}{ Q8. } & $r$ & & & & & & 1,00 & 0,61 & 0,57 \\
\hline & $P$ & & & & & & . & $<0,001$ & $<0,001$ \\
\hline \multirow[t]{2}{*}{ Q9. } & $r$ & & & & & & & 1,00 & 0,92 \\
\hline & $P$ & & & & & & & . & $<0,001$ \\
\hline
\end{tabular}


perception of person's, family and health professionals towards euthanasia. Moreover, the attitude towards death is followed by great discrepancy as an increasing number of individuals might control the way, time and place of their death in the future $[6,7]$.

According to this study, the level of knowledge of the relatives of critically ill patients on euthanasia and the currently used law in Greece on the end of life is not particularly high, since only $19.2 \%$ knew very much/ much on euthanasia. For most of the participants their main source of information was the media and press $(78.9 \%)$, while the knowledge they gained from their basic education was not sufficient (14.8\%) and was even less during the continuing education and postgraduate studies $(6.5 \%)$. This demonstrates the need for the enrichment of basic education programs on issues related to ethical dilemmas. The results of our study are confirmed by those of other studies which found that both education and public debate on euthanasia and the patient's own decision on death upon request when in an incurable state, led to a positive attitude towards the self management of the end of life [8-10].

In regards of the possibility to take initiative for the final decision on treatment approaches or will to death of their relative/friend, $73 \%$ of responders disagreed/ completely disagreed. A multicenter study conducted in 47 European countries on the public point of view on euthanasia, showed that Greece belongs to those countries whose statement on euthanasia is relatively poorer and is affected by the limited and restricted legislation on euthanasia in Greece [10]. The same results were published by the studies of Rietjenset et al. and Kemmelmeie et al. who discussed on perception of people of a "good death", with the acceptance of the pro-euthanasia agreement of "death with dignity" [11, 12].

Reliability of health systems for individuals is another matter. In a study of Köneke, acceptance of euthanasia by Greeks was found to be poor [13]. Therefore, in this study, relatives/friends would not take responsibility for the possible end of the life of their family or friend even after prompt information provided by health professionals. Relatives are not always willing to make decisions on behalf of the patient in such important matters. In a French study of patients hospitalized in the ICU, the researchers found that $53 \%$ of relatives did not want to participate in the decision-making [14].

Another possible explanation for our results could be the expectation that comes from advanced technology in the ICU enhancing hope of relatives/friends for patient's life expectancy. Technology can significantly prolong the patient's life, but can also increase psychological intensity of patients and their relatives when they have to make important decisions concerning the interruption or non-initiation of treatment for their patients [15].
In the present study we found that the more the APACHE II score increased the more positive were the participants when asked to give consent or decide to accelerate the end of life of the patient. Other important factors that would influence them were status severity, sense of pain and brain death. A number of international observational studies have come to the same clinical factors that contribute to non-escalation or withdrawal of treatment [16-20].

An important limitation of the study is that the population included came from a single hospital and a single ICU. Furthermore, response rate was not very high. The limited participation indicates that the Greek population is not yet ready to get involved in such discussions relating to major ethical dilemmas such as decisions about end of life.

\section{Conclusions}

The issue of euthanasia poses a challenge to every society. Publication and open discussion of euthanasia may have the potential to further permit the adoption of supportive attitude on euthanasia matters. Contribution of media and press has a major role in the issue. The decision on the management of the possible end of life is very important and often implicates patient's family. At this point, participation of the staff of the ICU may enlighten family and friends after providing professional advice and information.

\section{Acknowledgments}

Not applicable

\section{Funding}

No sources of funding to declare.

\section{Availability of data and materials}

Data sharing not applicable to this article as no datasets were generated or analysed during the current study.

\section{Authors' contributions}

$\Pi$ designed the manuscript and wrote the report. NG contributed in design of the study and review of the article, while EP contributed in collecting and analyzing the data. MD and SK participated in the interpretation of the data and carried out the statistical analysis. SS conceived the study. GZ and DT contributed in making the decision to submit for publication. All authors read and approved the final manuscript.

Ethics approval and consent to participate

Ethics approval by the Ethical Committee of Hippocration General Hospital of Athens in Greece, with the reference number 18531.

Consent for publication

Participants signed an informed consent in order to be included in the study.

Competing interests

All authors declare that they have no competing interests.

\section{Publisher's Note}

Springer Nature remains neutral with regard to jurisdictional claims in published maps and institutional affiliations. 


\section{Author details}

11st Department of Surgery, University of Athens, Hippocration General Hospital of Athens, 11527 Athens, Greece. 'Department of Cardiac Surgery, Hippocration General Hospital of Athens, 11527 Athens, Greece. ${ }^{3}$ Department of Blood Donation, Metaxa General Hospital of Athens, 18537 Athens, Greece. ${ }^{4}$ Cardiovascular Department of Surgery, Hippocration General Hospital of Athens, 11527 Athens, Greece. ${ }^{5}$ Head of ICU, Hippocration General Hospital of Athens, 11527 Athens, Greece.

Received: 28 May 2017 Accepted: 19 September 2017

Published online: 02 October 2017

\section{References}

1. Leenen HJ. Euthanasia, assistance to suicide and the law: developments in theNetherlands. Health Policy. 1987;8(2):197-206.

2. Zinn C. Australian voluntary euthanasia law is overturned. BMJ. 1997; 314(7086):994.

3. Cordner S, Ettershank K. Support for legalised euthanasia in Australia moves south. Lancet. 1996;348(9039):1439.

4. Admiraal P. Euthanasia and Assisted Suicide. In: Thomasma DC, Kushner TK, editors. Birth to Death: Science and Bioethics. Cambridge: Cambridge University Press; 1996. p. 207-17. Available from: http://euthanasia.procon.org.

5. Johnson K. "Montana Court to Rule on Assisted Suicide Case", The New York Times, Aug 31, 2009. Available from: http://www.nytimes.com/2009/09/01/ us/01montana.html.

6. Seale C. Changing patterns of death and dying. Soc Sci Med. 2000:51(6):917-30

7. Schroepfer TA, Noh H, Kavanaugh M. The myriad strategies for seeking control in the dying process. Gerontologist. 2009;49(6):755-66. doi:10.1093/ geront/gnp060. Epub 2009 Jun 8

8. Cohen J, Van Landeghem P, Carpentier N, Deliens L. Public acceptance of euthanasia in Europe:a survey study in 47 countries. Int J Public Health. 2014; 59(1):143-56. doi:10.1007/s00038-013-0461-6. Epub 2013 Apr 5

9. Ferreira N. Latest legal and social developments in the euthanasia debate: bad moral consciences and political unrest. Med Law. 26(2):387-407.

10. Cohen J, Marcoux I, Bilsen J, Deboosere P, van der Wal G, Deliens L. Trends in acceptance of euthanasia among the general public in 12 European countries (1981-1999). Eur J Pub Health. 2006;16(6):663-9. Epub 2006 Apr 26

11. Rietjens JA, van der Heide A, Onwuteaka-Philipsen BD, van der Maas PJ, van der Wal G. Preferences of the Dutch general public for a good death and associations with attitudes towards end-of-life decision-making. Palliat Med. 2006;20(7):685-92.

12. Kemmelmeier M, Wieczorkowska G, Erb HP, Burnstein E. Individualism, authoritarianism, and attitudes toward assisted death: cross-cultural, crossregional, and experimental evidence. J Appl Soc Psychol. 2002;32(1):60-85.

13. Köneke BMC Medical Ethics 2014, 15:86. Available from: http://bmcmedethics. biomedcentral.com/articles/10.1186/1472-6939-15-86/open-peer-review.

14. Azoulay E, Pochard F, Chevret S, Adrie C, Annane D, Bleichner G, et al. Half the family members of intensive care unit patients do not want to share in the decision-making process: A study in 78 French intensive care units. $\mathrm{C}$ Crit Care Med. 2004:32(9):1832-8.

15. Hadders $\mathrm{H}$. Enacting death in intensive care unit: medical technology and the multiple ontologies of death. Health (London). 2009;13(6):571-87. doi:10.1177/1363459308341869.

16. Esteban A, Gordo F, Solsona JF, Alia I, Caballero J, Bouza C, et al. Withdrawing and withholding life support in the intensive care unit: A Spanish prospective multi-centre observational study. Intensive Care Med. 2001:27(11):1744-9. Epub 2001 Oct 12

17. Ferrand $E$, Robert $R$, Ingrand $P$, Lemaire F. French LATAREA Gro up. Withholding and withdrawal of life support in intensive care units in France: A prospective survey. Lancet. 2001;357(9249):9-14.

18. Cook D, Rocker G, Marshall J, Sjokvist P, Dodek P, Griffith L, et al. Withdrawal of mechanical ventilation in anticipation of death in the intensive care unit. N Engl J Med. 2003;349(12):1123-32.

19. Wunsch H, Harrison DA, Harvey S, Rowan K. End-of-life decisions: A cohort study of the withdrawal of all active treatment in intensive care units in the United Kingdom. Intensive Care Med. 2005:31(6):823-31. Epub 2005 Apr 27

20. Yazigi A, Riachi M, Dabbar G. Withholding and withdrawal of life-sustaining treatment in a Lebanese intensive care unit: A prospective observational study. Intensive Care Med. 2005;31(4):562-7. Epub 2005 Mar 5

\section{Submit your next manuscript to BioMed Central and we will help you at every step:}

- We accept pre-submission inquiries

- Our selector tool helps you to find the most relevant journal

- We provide round the clock customer support

- Convenient online submission

- Thorough peer review

- Inclusion in PubMed and all major indexing services

- Maximum visibility for your research

Submit your manuscript at www.biomedcentral.com/submit
C) Biomed Central 